\title{
ESPORTES NA NATUREZA E ATIVIDADES DE AVENTURA: UMA TERMINOLOGIA APORÉTICA
}

\section{DR. GIULIANO GOMES DE ASSIS PIMENTEL}

Departamento de Educação Física, Universidade Estadual de Maringá; Programa Associado de Pós-graduação em Educação Física, Universidade

Estadual de Maringá/Universidade Estadual de Londrina

(Maringá - Paraná - Brasil)

E-mail: ggapimentel@uem.br

\section{RESUMO}

Este artigo analisa o conceito Esportes na natureza. Para tanto, por meio da hermenêutica dialética, analisa sua lógica interna. Considerando características como risco, imprevisibilidade, aventura, natureza, tecnologia e tendência histórica, a análise encontrou coerência, precisão e plasticidade no conceito de esportes na natureza. Porém, contrastando com a realidade, o termo esporte na natureza não abrange todas as práticas significativas (exclui atividades não-esportivas e aquelas que ocorrem em áreas urbanas). Portanto, o estudo desenvolve a inclusão desse termo em uma terminologia mais abrangente.

PALAVRAS-CHAVE: Terminologia; atividades de lazer; paradigma; linguagem. 
Embora a aventura, como experiência subjetiva da busca de emoções frente ao inusitado, talvez seja uma constante antropológica, é na contemporaneidade que se experimenta uma diversificação de atividades de aventura, na perspectiva do lazer. Em tese, elas estão ligadas a sensações de risco e vertigem, exacerbações controladas das emoções e, em muitos casos, congraçamento com a natureza e com outras dimensões sensíveis, cuja busca de revalorização aponta para um diferencial dessas práticas em relação aos esportes convencionais (BRUHNS, 2003; SCHWARTZ, 2006; MARINHO, 2008).

Nesse debate, concorrem diferentes propostas de delimitação do objeto: AFAN - Atividades Físicas de Aventura na Natureza (BETRAN, 2003), Práticas corporais de aventura (INÁCIO et al, 2005), Esportes radicais (UVINHA, 200I), Esportes na natureza (DIAS, 2007), esportes de ação (BRANDÃO, 20 I 0), entre outras propostas. As características listadas para cada termo nem sempre coincidem, mas é bastante recorrente a denominação esporte, seguida por algum adjetivo como vertigem, risco ou aventura.

Diante do não-estabelecimento de um acordo terminológico, há uma tendência em considerar que o debate não evoluiu o suficiente para possuir consensos sobre a delimitação do objeto. Esse 'consenso da falta de consenso' e especialmente a minimização dos supostos danos dessa indefinição às pesquisas na área poderiam resolver a questão. Afinal, além de se tratar de um objeto novo, ele não experimentou a estabilidade - havendo a manifestação de novas experiências, muitas das quais são não-usuais (como a espeleologia urbana), podendo chegar ao caráter desviante. Logo, a preocupação conceitual talvez seja uma precipitação quando o próprio objeto está parcialmente visível.

Porém, para outros, é quando o fenômeno está borrado que a definição acadêmica se faz mais necessária, pois faz emergir o objeto de onde antes só se viam manifestações isoladas. Segundo Dias (2007, p. 2), "a ausência de preocupações dessa ordem permite que sob a ideia de lazer esportivo na natureza proliferem muitos conceitos. Cada um deles descreve um campo muito amplo e variado de expressão desse fenômeno cultural." Enfim, segundo esse autor, a imprecisão seria algo academicamente prejudicial e sua resolução merece ser tratada como relevante.

Diante de tal problemática terminológica, o diálogo central do texto será com o autor Cleber Dias, analisando o conceito Esportes na natureza. Para tanto, a partir dos argumentos de sua defesa, se estabelece juízo crítico sobre essa categoria, refutando ou corroborando sua contribuição para o entendimento dessas manifestações lúdicas que, em tese, recorrem a novas tecnologias, se diferenciam 
ética e esteticamente dos esportes convencionais e evocam sensações e relações diferenciadas com o meio.

\section{ASPECTOS METODOLÓGICOS}

O presente texto dialoga com o texto de Dias (2007), no sentido de questionar/afirmar suas teses, contrapondo-as com a abrangência presente na noção de atividade de aventura. $\bigcirc$ objetivo, pois, do texto, é apontar limites e ganhos na definição de "esportes na natureza" evocada pelo autor (e colaboradores) para se referir aos esportes desenvolvidos em contato com a natureza. Este estudo teórico privilegia o debate com o texto "Notas e definições sobre esporte, lazer e natureza". Este não é o único trabalho no qual o autor externa sua preocupação terminológica, mas representa um esforço de aprimorar e sistematizar os trabalhos anteriores (DIAS; ALVES JÚNIOR, 2006, 2007; DIAS; MELO; ALVES JÚNIOR, 2007).

Para o debate, utilizamos a versão imediatamente lançada na revista Licere, a qual preserva uma nota de rodapé justificando a motivação do autor:

\footnotetext{
Embora este trabalho seja um esforço de aprimorar e sistematizar idéias que já haviam sido rascunhadas e mais ou menos anunciadas em outras oportunidades, a motivação definitiva para apresentá-lo nesses termos foi impulsionada, em larga medida, pelas discussões entabuladas nas conferências e pelas conversas informais estabelecidas nos bastidores do II Congresso Brasileiro de Atividade de Aventura. Nesse sentido, especial agradecimento aos amigos Giuliano Pimentel, Ricardo Uvinha e Alcyane Marinho que, com suas objeções e discordâncias, contribuíram para tais formulações. Imagino - e espero que continuamos divergindo de quase tudo que está colocado aqui. (DIAS, 2007, p. I).
}

Para análise e discussão do material utilizou-se a dialética hermenêutica, no seu sentido clássico, como procedimento filosófico de diálogo entre teses contrárias e da busca do(s) sentido(s) postos em cada tese. O texto caracteriza-se como ensaio, isto é, uma reflexão descritivo-discursiva, dedicando-se à apresentação compreensiva e à discussão de um determinado tema de interesse acadêmico.

\section{ESPORTES NA NATUREZA: UM CONCEITO}

Primeiramente, Dias (2007, p. 9) não insere "esportes na natureza" como uma categoria geral para designar todas as práticas às quais outros autores tentam agrupar em termos como AFAN, esportes de aventura ou radicais. Seu alvo é "o esporte como uma prática que estabelece relações intersubjetivas com a natureza, a fim de extrair prazer dessa interação". É justamente isso que o conceito possui de mais decepcionante e, ao mesmo tempo, mais producente. Não se propõe 
ao conjunto de práticas, mas àquelas que possuem a codificação esportiva nítida (mountain bike, voo livre, rafting, montanhismo entre outros) ou em potência.

Em termos pragmáticos, em sua perspectiva, deve haver uma forma de, por exemplo, afirmar se descer o rio numa boia é um esporte na natureza. Dias (2007), tendo o lazer como referência, foge do tipo ideal de esporte, proposto por Gutmann ( 1978), para quem o esporte moderno deve ter regulamentos, burocracia, profissionalização, secularismo, e recordes. Os critérios para o esporte na natureza são outros: baixo nível de previsibilidade, menor estereotipia dos movimentos, disposição ao risco, busca por emoções, presença de novas tecnologias e, claro, o contato com a natureza. Nesse caso, é aceitável como esporte na natureza até mesmo aquela experiência feita por meio de bricolagem de técnicas esportivas (bungee jumping, rapel, espeleologia, boia-cross).

Para o autor, um critério precedente aos demais seria o fato histórico: a Modernidade produziu, entre outros fenômenos, a busca pela natureza para a prática esportiva. Tal dinâmica seria forte para justificar um nexo entre diferentes esportes, visto que cada um deles "responde a um mesmo conjunto de demandas colocadas pelas mesmas circunstâncias históricas gerais” (DIAS, 2007, p. 26).

Mas será que antes da Modernidade não havia esporte na natureza? Entre os romanos eram comuns as idas (turísticas) ao campo e ao mar, como opção de ócio. Entre eles, esportes eram difundidos como diversão competitiva e dedicados aos deuses (boa parte deles ligados à natureza, como Diana e Netuno). Em decorrência, a caça e natação não estão até hoje persistindo como esportes na natureza? Então, como Dias se atreve a tratar dos esportes na natureza como fruto de uma tendência moderna de aliar esporte e natureza?

Tanto o que consideramos como esporte e natureza na atualidade, foi mudando até o ponto presente, quando esses conceitos são apreendidos a partir de uma mentalidade moderna. Seguramente, nas sociedades ocidentais avançadas não é a mitologia ou a religião os filtros axi-teleológicos desse fenômeno. Portanto, o termo esporte na natureza, ao mesmo tempo em que pode ser remetido a predecessores arcaicos, diz respeito a algo conhecido e compreendido na atualidade.

Cleber Dias não inova ao relacionar essas práticas com um mesmo movimento histórico, visto que outros autores, como Betrán (2003) em relação às AFAN na Pós-modernidade, também situam essas práticas em unidade com o tempo presente. Porém, seu recorte é mais apurado, mais objetivo e, consequentemente, formal. Mas será isso suficiente?

Primeiro se questiona a adoção do termo esporte. Recorrendo a estudo que abordou as pessoas comuns do cotidiano sobre o que entendiam por atividades de aventura, a maioria associa aos esportes e ao turismo de aventura, com pequenas citações a lazeres desviantes e a lutas (PIMENTEL; SAITO, 20 I 0). Logo, a escolha 
pelo esporte é uma opção teórica por um fenômeno quase-hegemônico até mesmo entre a população não-praticante.

Segundo, a escolha pelo adjetivo "na natureza" é melhor que o "de aventura"? Há de se notar que a aventura não é um fator central na análise de Dias, pois a aventura emerge - direta ou indiretamente - como desafio às forças naturais. Como se prioriza os esportes praticados em áreas naturais, poderia ser previsível, neste caso, uma apologia ao ambiente natural. Porém, com o necessário ceticismo, o autor nos livra da necessidade em colar o rótulo ecológico ou ambiental, ao esporte na natureza. Com felicidade o termo "na" situa mais uma localização do que uma identificação com causas ambientais. Isso rompe, em certa medida, a tradição de estudos a partir dos trabalhos e orientações de Heloisa Bruhns, os quais investigam aproximações de tais práticas com uma sensibilidade ecológica. Aliás, é possivelmente graças a tais estudos, relativamente pioneiros, que o enfoque 'romântico' sobre a integração com a natureza sofreu relativizações.

Outro problema relacionado à qualificação desse esporte como sendo na natureza, é o tom excludente ao universo urbano. Para Dias (2007, p.9), mesmo havendo atividades em ambientes artificiais, como o skate, "boa parte dos seus símbolos foram produzidos originalmente em interface com as práticas desenvolvidas em ambientes naturais." Porém, esse argumento corrobora para uma relação intrínseca entre urbano e natural que talvez fosse ser unificada por alguma outra categoria. $O$ próprio tema do V Congresso Brasileiro de Atividades de Aventura (CBAA 20 I 0) já foi provocativo nesse sentido: "Entre o urbano e a natureza: a inclusão na aventura".

Dias não é enfático quanto à diferença entre "esportes de aventura" e "esportes na natureza", mas parece compartilhar do entendimento que a natureza, pela imprevisibilidade e riscos, implicaria a aventura. Logo, se a aventura é uma categoria nativa, por que não esportes de aventura? Porque "a aventura e o risco que se procura, realiza-se no enfrentamento dos desafios naturais tais como eles se apresentam. [...] Enfim, a audácia e a aventura são favorecidas pelo encontro corporal do esportista com os elementos da natureza" (DIAS, 2007, p. 21).

Um último questionamento é o motivo de um termo mais abrangente como "atividade" ou "prática" não ser preferido. Parece-me que "esporte", por ser uma categoria acadêmica e nativa, além de ser histórica, daria mais força para aceitação ao invés de uma designação genérica. De fato, o uso do termo nature sports é producente nas buscas em repositórios acadêmicos e sites de consulta.

Em suma, a proposição de Dias é a de um objeto que, conforme suas fontes bibliográficas (de acadêmicos e de praticantes), vem para situar um determinado grupo de práticas: as esportivas e, mais especificamente, aquelas que acontecem na natureza. Seu conceito não é confuso, embora limitante. Trata historicamente 
das práticas ligadas à moderna fruição estética da natureza em parceria com a esportivização dos divertimentos. Assim,

\begin{abstract}
Grosso modo, ao falarmos do conceito de esportes na natureza estamos falando então de um conjunto de modalidades cuja posição dentro do espaço esportivo mais geral corresponde a um jogo regulamentado realizado na natureza e assentado na proeza física, em que níveis variáveis de seriedade e ludicidade, cooperação e competição, amadorismo e profissionalismo, sensibilidade e insensibilidade ecológica, intervêm simultaneamente, variando de acordo com a perspectiva da atividade, mas sem nunca escapar a esse esquema geral. Tal definição diz respeito, portanto, ao fenômeno mais geral e não se restringe a técnica corporal. (DIAS, 2007, p. 26-27).
\end{abstract}

Essa descrição revela uma dificuldade em situar sinteticamente a categoria. Não por menos. As categorias concorrentes trazem características muito próximas das postas por Dias (2007). Porém o autor, já não alimenta a visão dicotômica e idealista ainda presente em produções da área, as quais emitem julgamentos de valor, positivando a aventura. Dias, entre ver esportes na natureza como algo bom ou ruim, é rigoroso ao apontar que a realidade abarca algumas polaridades. Abarcando a ambiguidade, essas modalidades contemplam seriedade e ludicidade, cooperação e competição, amadorismo e profissionalismo, sensibilidade e insensibilidade ecológica. Logo, não podem ser essas características, na qualidade de variáveis, que venham a definir o esporte na natureza.

Se visto sob esse ponto, esse conceito rascunhado não diz muito sobre o ser humano e nem sobre a dinâmica produzida na prática. Mas situa uma tendência histórica em se praticar esporte na natureza, remontada claramente desde o Século XIX. Por isso, mesmo essas práticas - tomadas como "esportes"- apresentando "novas peculiaridades", "não parecem se apresentar como ruptura com os formatos multifacetados do campo esportivo. Antes parecem mais desdobramentos desse processo contínuo e tenso de configuração" (DIAS; MELO ALVES JÚNIOR; 2007, p. 365).

Extrapolando os argumentos do autor, isso pode ser ilustrado com o surf, ao qual se poderiam imprimir inclusões, exclusões e zonas de indefinição a serem resolvidas conforme a análise do contexto. Não há dúvidas em rotular o surf se ele é praticado no mar, no rio ou em outro 'lugar natural' (entramos na dificuldade, por vezes em decidir o que é cultural e o que é natural). Independente do contexto (competição, clube, hotel, escolinha) as variáveis não alteram o conceito. Todavia, o surf na piscina artificial ou no simulador já seria outra coisa? É um objeto rumo à autonomia (como a espeleologia urbana) ou mantêm relações com a prática de origem? Em caso da segunda alternativa, como pensar em dois objetos similares e complementares, mas que sejam conceitualmente diferentes só por conta do ambiente onde foram vivenciados? 
Portanto, embora olhe para o fenômeno histórico mais geral ao invés do movimento em si, o autor é formal em vaticinar que a totalidade se exaure no entendimento dinâmico de esporte na natureza. Coerentemente, o mesmo, por exemplo, retira as interseções com o turismo de sua análise. Outras tantas práticas, ou são enquadradas num conceito mais aberto e inclusivo de esporte ou dirão respeito a qualquer outro fenômeno, num processo de assepsia. Para ilustrar como o tal do "impulso histórico" pode vir fragmentado no conceito de esporte na natureza, provocativamente, criei a seguinte narrativa:

PP e BJ são adolescentes cariocas, residentes no Morro da Formiga, favela ao lado do Parque Nacional da Tijuca. Nessa floresta, nossos heróis resolveram passar a noite acampando, tendo utilizado a tarde para fazer piquenique e passear pelas trilhas de aventura. PP saca uma trouxinha de maconha e junto com BJ resolvem fazer o consumo recreativo daquela droga. Estão contemplando as estrelas e o canto noturno dos pássaros, quando começa a chover, formando corredeiras. BJ tem a ideia de utilizar um pedaço de tábua para realizar uma espécie de surf morro abaixo. PP adere à prática, mas sem uso de material, desce rolando, tendo, inclusive ficado nu. Os dois são flagrados pela vigilância do Parque e perseguidos pela mata, tendo de subir em frondosas árvores e se camuflar nelas. Passadas algumas horas, retornam furtivamente ao local do acampamento, tendo capturado pelo caminho um tatu, que lhes servirá de refeição.

Tal experiência não poderia ser tachada dentro de um esporte ou mesmo de uma nomenclatura específica. Diz respeito à dinâmica social ou à busca pela concretização de uma multiplicidade de interesses no tempo livre. De certa forma, experiências como essas abalam o entendimento dominante que foi construído sobre o conceito de lazer. Elas combinam, ludicamente, o lazer desviante, a aventura, a juventude, o risco, o contato com a natureza (seja como cenário ou como parceira; essa moralidade não importa). Por que, então, se as experiências reais divergem do próprio conceito de lazer, devemos construir uma barreira conceitual entre essas vivências na natureza e vivências de outra ordem ou codificação, que também ocorrem na natureza, às quais chamaríamos de esporte?

Não se trata de miopia do autor. Ele não desconhece que estão em jogo perspectivas teóricas diferentes, que lutam por um modelo e um paradigma de padronização conceitual, participando desta disputa inclusive aqueles que participam do consenso de que não há consenso. Dias (2007, p. 29) concorda que "as multiplicidades e divergências, tanto entre os praticantes, quanto entre acadêmicos, remetem as disputas que toda estrutura semântica/inguística está submetida". Mas, ainda assim, sua posição é pela busca da "objetividade nas operações conceituais". Essa luta pelo conceito se justifica porque não é possível teorizar sobre algo sem o uso de conceitos. Enfim, como haver um estatuto científico sobre algo que não conseguirmos nomear? 
Mas ao criar essa margem de exclusão, para assegurar um objeto mais ou menos limpo, se corre o risco de comprometer-se numa concepção racionalista de ciência, pois, faz assepsia das dinâmicas para chegar a um objeto puro. Tomando emprestadas as palavras de Maffesoli (200 I , p. 47): "Ao nomear, com excessiva precisão, aquilo que se apreende, mata-se aquilo que é nomeado." Procedimento este complexo de ser levado nas ciências humanas e sociais. Ainda segundo o mesmo autor,

nas ciências da natureza, o racionalismo puro e duro está em perfeita congruência com seu objeto. Este está imóvel, estável, há pouca ou nenhuma interferência entre ele e o observador que supostamente o analisa. Por conseguinte pode-se aplicar-lhe, do exterior, uma série de leis que são, também elas, impassíveis. (MAFFESOLI, 200 I, p. 48).

Essa ponderação sobre os problemas datados no modo de produção do conhecimento na Modernidade não diz respeito especificamente à esclerose dos conceitos rígidos (o que não parece ser o caso de Dias). Até é fecundo ao conhecimento que os conceitos sejam construídos, mas também pode ocorrer de serem abandonados e ressignificados com as mudanças no fenômeno. Diante desta premissa, cabe à comunidade acadêmica discutir quais conceitos são fundamentais para haver densidade teórica na análise das dinâmicas.

\section{CONCEITOS QUE SE FERTILIZAM MUTUAMENTE}

Segundo Deleuze e Guattari (2007, p. 27), "não há conceito simples. Todo conceito tem componentes, e se define por eles." Assim, nunca é algo fechado em si, mas carrega a multiplicidade (por isso, os conceitos diferentes sobre o mesmo objeto nos parecem tão parecidos?). A missão do intelectual no tempo presente é produzir conceitos novos para acompanhar a dinâmica de situações que surgem em velocidade e profusão na atualidade. Um conceito, mesmo universal, não abarca tudo. É necessário sair do caos para circunscrever um "universo que os explica". Adjuntam ainda os autores que, como os conceitos nominais são de compreensão finita, parece inevitável que seu contorno seja irregular, necessitando a contínua revisão e diálogo com outros conceitos, incluindo a possibilidade de sobreposição e justaposição. Salvaguardada essa premissa, parto para pensar numa proposição com desdobramentos sobre o Esporte na natureza em Dias dialogando com outra categoria usual no Brasil: atividades de aventura.

Comparando com o mundo empírico, a proposta terminológica Esportes na natureza, de Dias (2007), é: objetiva e adequada para manifestações como Corrida de aventura, Montanhismo e Surf; subjetiva e adequada para manifestações como 


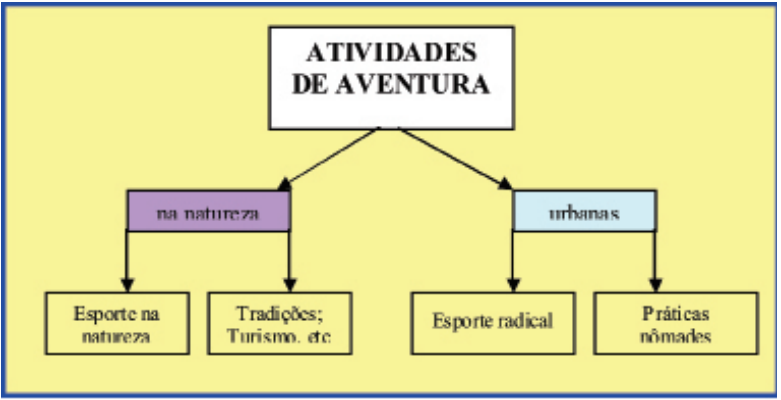

Figura I. Esquema Eclético com subdivisões por ambiente

Arvorismo, Acampamento, Trilha ecológica; e objetiva e inadequada para manifestações como Parkour, Skate e BASE Jump. Subjetivo porque depende do autor tê-las como esporte enquanto não são - no sentido restrito- tomadas como tal, embora o termo seja adequado em relação a ocorrerem na natureza (ou a ela se remeterem). Assim, é admissível que essa proposta seja eficaz para cobrir certa superfície e que seria o caos exigir abranger todas as manifestações implicadas.

Não por menos, no atual estágio conceitual do campo, o movimento brasileiro é de notório ecletismo, com diversas correntes. Uma delas apresenta uma orientação crescente para acomodar o objeto como sendo atividade de aventura. Esse, sem dúvidas, é mais um conceito que poderia gerar debates seminais e, especialmente, orientar a tessitura de uma organização conceitual. Para ilustrar a capacidade analítica desse termo, especialmente em relação ao eixo espaço, componho a ilustração abaixo:

O eixo espacial é uma das articulações mais fortes nas publicações, pois a referência a ar, água e terra está presente em muitas das diferentes nomenclaturas (PARLEBAS, 1988; UVINHA, 200I; MARINHO, 2008). Enfim, essa tríade é uma questão pretensamente pacífica' entre os estudiosos, pois a aventura se dá na interação não-usual com um ou mais desses tipos de ambiente. Se esses três elementos são acessados na natureza ou em intervenções arquitetônicas, isso não é tão relevante como o são as ações e as representações que o sujeito produz nessas experiências lúdicas de risco calculado.

Assim, o conceito atividades de aventura parece resguardar a reconhecida e problemática generalidade de experiências que podem estar ocorrendo no

1. Com o desenvolvimento de novas tecnologias, o virtual tende a afrontar a necessidade de sair de casa para se alcançar as sensações associadas à aventura. 
ambiente natural (turismo, educação ambiental, esportes, rituais indígenas) e no citadino (esportes, jogos, entre outros). Esse "e" está em destaque para realçar a possibilidade de a mesma manifestação ocorrer em mais de um meio. E não se trata da linearidade na qual esportes urbanos, como skate e escalada, são cópias de práticas em ambientes naturais. Vê-se que simultaneidade e mútua fertilização estão também presentes, como é inconteste no Geocaching (VIANA, 20 I I), uma espécie de caça ao tesouro em locais públicos urbanos, utilizando o Sistema Global de Posicionamento (GPS), sem representar imitação das corridas de aventura com GPS. Importa, em síntese, que ambas as práticas implicam no uso não-usual do espaço, subvertendo a rotina em riscos calculados, daí serem atividades de aventura.

Os termos utilizados na ilustração acima buscam situar a diversidade de práticas que pode ser compreendida a partir da enunciação atividade de aventura. Conforme discutido, o termo esporte na natureza não engloba sequer as formas de lazer no ambiente natural, visto que tradições (como a caça), turismo (sob os mais variados rótulos), escotismo e campismo escapam ao cenário esportivo. É na e pela natureza que essas manifestações, pela ação e representação humana, conceituam o próprio ambiente natural, dado que, conforme Deleuze e Guattari (2007), a natureza não tem consciência de si. Portanto, é a consciência humana que nomeia o meio a partir das relações (imaginárias ou atuais) estabelecidas.

No tocante às práticas urbanas, é necessário enxergar a relação, mas também a práxis distinta, entre o que se convencionou chamar de esportes radicais (extreme games) e as práticas nômades na cidade. No primeiro caso, há crescente processo de normalização. De certo modo, as várias modalidades esportivas de skate, patins in-line, BMX e as versões urbanas de surf e de escalada já se encontram disciplinadas, levando a sua ocorrência se dar em ambientes estandardizados. De outro lado, skate de rua e downhill, geocaching, espeleologia urbana, rapel, slackline, BASE Jump e parkour ainda são predominantemente práticas urbanas de exploração não-usual da arquitetura citadina. Essas práticas são geralmente nômades, pois os 'points' (galerias de esgoto, prédios, ruas, pontes, antenas, monumentos) podem ser interditados para a prática, resultando em transgressões ou busca por novos lugares. É importante destacar que as aventuras urbanas estão mais sujeitas à domesticação, mesmo aquelas postas à margem. A criação de parques para parkour ilustra a dinâmica do biopoder em buscar seduzir as heterogeneidades urbanas em nome da segurança. Já no ambiente natural isso parece manifestar-se mais no 'fetichismo tecnológico', pois implementos mais avançados são tomados como produtivos e seguros.

Interessa destacar que o termo atividades de aventura, a exemplo de esporte na natureza, vai nomear práticas vivenciadas como lazer. Portanto, a aventura relacionada, por exemplo, às descobertas científicas, à exploração profissional de terras 
desconhecidas ou à tensão das profissões que envolvem risco, embora compartilhem de um similar impulso lúdico, não vêm sendo objetos preferenciais de estudo.

Embora o consenso de não haver consenso seja prudente, não se pode fazer a apologia desse quadro. A comunidade precisa dar continuidade às buscas já iniciadas, como no caso da Comissão de esportes de aventura (CEAV) composta pelo Ministério do Esporte para discutir as políticas nesse segmento e que, como primeira produção, teve de adotar conceitos para operacionalizar o diálogo entre os 19 integrantes da CEAV (MARINHO, 2007).

Definir o que são essas modalidades de aventura é certamente uma questão de poder. Por isso, mesmo para o mercado, não se trata de meras palavras. Elas vêm subsidiando projetos de lei (como 7.288/20 I0), com fins pragmáticos e consequências na atuação profissional em Educação Física. Ao dizer, por exemplo, se o trekking é turismo ou esporte, se legaliza a quem o profissional de aventura deve sujeitar-se (ou à Associação Brasileira de Empresas de Turismo de Aventura ou às entidades esportivas ou ao Conselho Federal de Educação Física) e, consequentemente, quais normalizações irá seguir.

\section{CONCLUSÃO}

O esforço de Dias em combater o ecletismo no campo não se anuncia como uma imposição semântica ou vaidade acadêmica. Sua justificativa epistemológica está em determinar, afinal, qual é o objeto a ser estudado: é o esporte ou algo mais amplo? Se for o esporte, é de qual tipo: aquele que ocorre na natureza, o relacionado ao não-convencional, o atravessado pelos signos do risco ou aquele que evoca aventura? Seja qual for a resposta, um será o eixo e os demais estudados como foco secundário.

Nesse sentido, a preocupação com os conceitos é pertinente, pois poderá permitir uma identidade e um olhar mais preciso às pesquisas. Considerando o desenvolvimento teórico desse campo, o debate sobre terminologia, tipologia e paradigmas é obrigatório para evitar um objeto amplo destituído de profundidade. Essa não é, contudo, uma tarefa fácil, pois os termos refletem escolhas teóricas e epistemológicas. Se as categorias, em certa medida refletem a cristalização do pensamento, é necessário refinar o debate antes de se fazer as escolhas.

A resposta de Dias foi buscar fontes nas literaturas acadêmica e nativa. Mas esse diálogo precisa ser aprofundado porque o estado da arte ainda não foi feito; e pode até não ser viável ainda. Em boa parte, tanto no exterior quanto no Brasil, os pesquisadores ainda se debruçam sobre a 'forma' do fenômeno. A cada novo movimento, novas definições e organizações do campo surgem. Isso significa ou 
que os pesquisadores estão 'dando voltas' em torno da superficialidade do objeto sem encontrar sua 'essência'- ou que, realmente, não se conhece toda a superfície.

É insofismável que o conceito esportes na natureza tem base histórica e coerência interna para agregar uma série de modalidades que interagem com valências naturais em terra, ar e água. É fundamental para se trabalhar terminologicamente com rigor as práticas com codificação esportiva presentes em ambiente natural. Porém, esse termo é limitado frente ao caos de práticas sinergicamente entrelaçadas no tempo presente. Sob essa categoria, seriam excluídas à análise atividades como acampamento, birdwatching ou o arvorismo, por não serem esportes? E o que se dirá de outras práticas, algumas esportivas, típicas da interação com o urbano e bem divergentes das intenções do esporte do Século XIX?

Ademais, em um movimento negativo, não seria toda essa discussão precipitada ou, pior ainda, uma perigosa especialização dos objetos, redundando na fragmentação do saber? Eis o perigo de criarmos um pseudo-objeto, pura representação como se a força própria de nossas ideias determinasse a realidade. Como as verdades científicas são provisórias, vale relembrar a sabedoria dos gregos cuja Filosofia elegera a prudência como maior das virtudes. A comunidade na questão terminológica ainda estabelece um diálogo aporético, logo, inconclusivo. Portanto, o consenso de não consenso, se não enraizado na preguiça intelectual, pode ser a medida da razão nestes tempos, necessitando haver mais explorações e debates antes de fechamentos teóricos mais perenes.

Há necessidade em aprimorar o debate teórico, bem como trazer mais dados empíricos para o confronto com as ideias. Um dos desdobramentos futuros dessa reflexão, por exemplo, seria investigar aspectos qualitativos e fenomenológicos da experiência dos praticantes das ditas modalidades. Seriam elas desveladas como na natureza, esportivas, de aventura?

Destarte, para o momento, a abertura terminológica torna factível a adoção de um conceito abragente: atividades de aventura. Atividade de aventura vai tratar da busca deliberada -e no tempo livre- por experiências não-usuais as quais culturalmente apreendemos como sendo aventura (corriqueiramente associada a sair do cotidiano e entrar no imprevisto), considerando a especificidade do ambiente onde ocorram. Mais que um vocábulo 'guarda-chuva', atividades de aventura (apesar das críticas que o termo 'atividade' recebe na Educação Física) pode apenas tratar-se de uma solução provisória para uma comunidade que carece de discussão acumulada para alçar novos patamares conceituais. 


\section{Sports in the Nature and Adventure Activities: \\ an unfinished Terminology}

ABSTRACT: This paper analyzes the concept of Sports in nature. Thus, by the dialectical hermeneutics, this article reviews the internal logic of that concept. Considering features such as: risk, unpredictability, adventure, nature, technology and historical trend, the analysis met accuracy and plasticity in the concept sports in nature. However, observing the reality the term "sport in nature" covers many significant practices, but not all (this excludes non-sports activities and those that occur in urban areas). Therefore, the study concludes that this term must be included in a more comprehensive terminology.

KEYWORDS: Terminology; leisure activities; paradigm; language.

\section{Deporte en la naturaleza y actividad de aventura: una terminología aporética}

RESUMEN: Este artículo examina el concepto de deporte en la naturaleza. Con este fin, a través de la dialéctica hermenéutica, analiza su lógica interna. Teniendo en cuenta características tales como riesgo, incertidumbre, aventura, naturaleza, tecnología y tendencias históricas, el concepto de deporte en la naturaleza tiene consistencia, precisión y plasticidad segundo el análisis. Sin embargo, en contraste con la realidad, la palabra deporte en la naturaleza no cubre todas las prácticas significativas (por ejemplo, las actividades en ciudad y otras que no son deportes). En conclusión, el estudio desarrolla la inclusión de este término en una terminología más amplia.

PALABRAS CLAVE: Terminología; actividades recreativas; paradigma; lenguaje.

\section{REFERÊNCIAS}

BETRÁN, J. O. Rumo a um novo conceito de ócio ativo e turismo na Espanha: as atividades físicas de aventura na natureza. In: BRUHNS, H. T.; MARINHO, A. (Org.). Turismo, lazer e natureza. São Paulo: Manole, 2003. p. I57-202.

BRANDÃO, L. Esportes de ação: notas para um estudo acadêmico. Revista Brasileira de Ciências do. Esporte, Florianópolis, v. 32, n. I, p. 59-73, 2010.

BRUHNS, H. T. No ritmo da aventura: explorando sensações e emoções. In: BRUHNS, H. T.; MARINHO, A. (Org.). Turismo, lazer e natureza. São Paulo: Manole, 2003.

DELEUZE, G.; GUATTARI, F. O que é a filosofia? São Paulo: Editora 34, 2007.

DIAS, C. A. G.; ALVES JÚNIOR, E. D. Notas conceituais sobre esportes na natureza. Lecturas: Educación Física y Deportes, Buenos Aires, ano 12, p. I |4, 2007.

DIAS, C. A. G. Notas e definições sobre esporte, lazer e natureza. Licere, Belo Horizonte, v. 10, n. 3, p. I-36, 2007. 
DIAS, C. A. G.; MELO, V.; ALVES JÚNIOR, E. D. Os estudos dos esportes na natureza: desafios teóricos e conceituais. Revista Portuguesa de Ciências do Desporto, Porto, v. 7 , p. 65-95, 2007.

DIAS, C. A. G.; ALVES JÚNIOR, E. D. Conceptual notes regarding the sports in nature. FIEP Bulletin, Foz do Iguaçu, v. 76, p. |4| - |44, 2006.

GUTTMANN, A. From ritual to record: the nature of modern sports. New York: Columbia, 1978.

INÁCIO, H. L. D. et al. Travessuras e artes na natureza: movimentos de uma sinfonia. In: SILVA, A. M.; DAMIANI, I. R. (Org.). Práticas corporais. Florianópolis: Nauemblu, 2005. p. 8I - 105.

MAFFESOLI, M. Elogio da razão sensível. 2. ed. Rio de Janeiro: Vozes, 2001.

MARINHO, A. Relato da participação do CBCE na Comissão de Esporte de Aventura/Ministério do Esporte. Florianópolis (SC), 26 de abril de 2007. Disponível em: http://www.cbce.org.br/ br/acontece/materia.asp?id=220. Acesso em: 19 abr. 2011 .

MARINHO, A. Lazer, aventura e risco: reflexões sobre atividades realizadas na natureza. Movimento, Porto Alegre, v. 14, n. 2, p. 181-206, 2008.

PARLEBAS, P. Perspectivas para uma Educación Física moderna. Andalucia: Quisport, 1988.

PIMENTEL, G, G. A.; SAITO, C. F. Caracterização da demanda potencial por atividades de aventura. Motriz, Rio Claro, v. 16, n. I, p. I52-161, jan./mar. 2010.

SCHWARTZ, G. M. (Org.). Aventuras na natureza: consolidando significados. Jundiaí: Fontoura, 2006.

UVINHA, R. R. Juventude, lazer e esportes radicais. Barueri: Manole, 200 I.

VIANA, J. A. A mobilidade como aventura na cidade: jogos baseados em geolocalização (gps) e apropriação urbana. Movimento, Porto Alegre, v. 17, p. 237। -25 I, 20 I I.

Recebido em: 16 ago. 201 I

Aprovado em: 01 out. 2011

Endereço para correspondência: Grupo de Estudos do Lazer/DEF/UEM Avenida Colombo, 5.790

Maringá-PR CEP: 87.020-900 